\title{
Vaginal Cancer pM1 TNM Finding v7
}

National Cancer Institute

\section{Source}

National Cancer Institute. Vaginal Cancer pM1 TNM Finding v7. NCI Thesaurus. Code C89471.

Vaginal cancer with distant metastasis. (from AJCC 7th Ed.) 